University of Denver

Digital Commons @ DU

Graduate School of Social Work: Faculty

Scholarship

$12-2020$

\title{
How Peer Support Specialists Uniquely Initiate and Build Connection with Young People Experiencing Homelessness
}

\author{
James Erangey \\ Community Based Researcher, USA \\ Connor Marvin \\ Community Based Researcher, USA \\ Danielle Maude Littman \\ University of Denver, danielle.littman@du.edu \\ Meredith Mollica \\ Community-based Researcher and Former Staff at Colorado Coalition for the Homeless \\ Kimberly Bender \\ University of Denver, kimberly.bender@du.edu
}

See next page for additional authors

Follow this and additional works at: https://digitalcommons.du.edu/gssw_facultyscholarship

Part of the Community-Based Research Commons, Mental and Social Health Commons, and the Social Work Commons

\section{Recommended Citation}

Erangey, James; Marvin, Connor; Littman, Danielle Maude; Mollica, Meredith; Bender, Kimberly; Lucas, Tom; and Milligan, Tara, "How Peer Support Specialists Uniquely Initiate and Build Connection with Young People Experiencing Homelessness" (2020). Graduate School of Social Work: Faculty Scholarship. 5. https://digitalcommons.du.edu/gssw_facultyscholarship/5

This Article is brought to you for free and open access by the Graduate School of Social Work at Digital Commons @ DU. It has been accepted for inclusion in Graduate School of Social Work: Faculty Scholarship by an authorized administrator of Digital Commons @ DU. For more information, please contact jennifer.cox@du.edu,digcommons@du.edu. 


\section{Authors}

James Erangey, Connor Marvin, Danielle Maude Littman, Meredith Mollica, Kimberly Bender, Tom Lucas, and Tara Milligan 
How Peer Support Specialists Uniquely Initiate and Build Connection with Young People Experiencing Homelessness

James Erangey ${ }^{\mathrm{a}}$, Connor Marvin ${ }^{\mathrm{b}}$, Danielle Maude Littman ${ }^{\mathrm{c}}$, Meredith Mollica ${ }^{\mathrm{d}}$, Kimberly

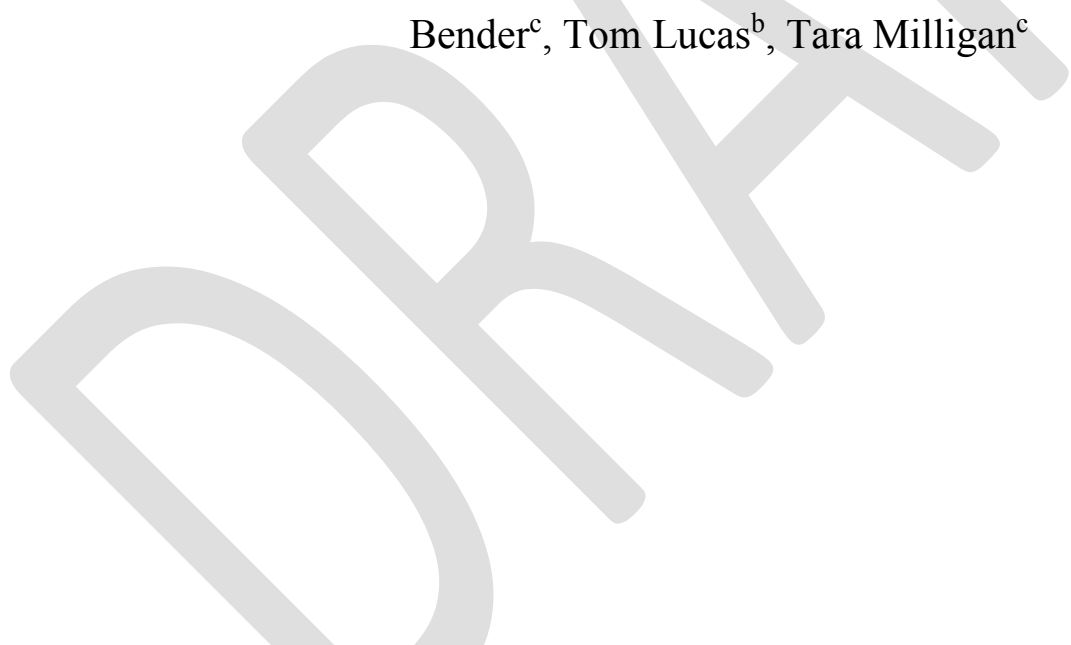

${ }^{a}$ Community-based researcher

${ }^{\mathrm{b}}$ Colorado Coalition for the Homeless, 2111 Champa St., Denver, CO, 80205

${ }^{\mathrm{c}}$ Graduate School of Social Work, University of Denver, 2148 S. High St., Denver, CO 80208, USA; danielle.littman@du.edu; kimberly.bender@du.edu

${ }^{\mathrm{d} C}$ Community-based researcher and former staff at Colorado Coalition for the Homeless, 2111 Champa St., Denver, CO, 80205 


\section{Introduction}

Numbering 3.5 million in the United States (Morton, Dworsky, \& Samuels, 2017), young people experiencing homelessness are defined as persons under age 25 who lack regular, fixed, and adequate nighttime residence, including young people in transitional or emergency shelters, sleeping outside, and couch surfing (42 U.S.C. $§ 11434 \mathrm{a}[2][\mathrm{B}])$. Although various factors facilitate vulnerabilities to homelessness, a predominant pathway for youth is family conflict (National Center for Homeless Education, 2012). Young people may also leave home because of sexual abuse, physical abuse, family financial crisis, and unstable temporary housing, among other reasons (Barrett, 2019). By the time young people become homeless, they may have been exposed to multiple, ongoing, and pervasive traumatic experiences such as abuse, neglect, or domestic violence (Keeshin \& Campbell, 2011), and living with an adult caregiver who copes with mental illness or substance misuse (Combs et al., 2020).

While the causes of youth homelessness are rooted across the individual, social, and systemic landscape and impact everyone uniquely, several factors are associated with amplified vulnerability to homelessness. Young people who have been involved in the foster care and juvenile justice systems experience higher rates of homelessness or housing instability (Britton \& Pilnik, 2018; Dworsky et al., 2019), as do youth with historically oppressed identities, including Black, Indigenous, and Latinx youth (Aceves, et al., 2020; Morton, et al., 2018a; Morton, Chavez, \& Moore, 2019) and those identifying as lesbian, gay, bisexual, transgender, and/or queer (LGBTQ) (Morton et al., 2018b). Young people experiencing homelessness often face intersecting systemic injustice, including limited access to healthcare, disjointed educational experiences, and generalized stigmatization and oppression (Kidd, 2007; Rahman, Turner, \& Elbedour, 2015). 
Service systems are often poorly equipped, inflexible, or otherwise unsuccessful at engaging youth experiencing homelessness (Altena et al., 2017). Even when they desire support, young people often do not engage with conventional homelessness services (Hudson et al., 2010; Kurtz, Lindsey, Jarvis, \& Nackerud, 2000) due, in part, to adaptive distrust of formal support systems (Auerswald \& Eyre, 2002). Stigma and discrimination, particularly around mental health needs, may further deter youth from seeking formal support (Hudson et al., 2010). Given this history, young people may be apprehensive to engage service providers when offered the opportunity (Naert et al.,2019). Even when relationships between service providers and youth are initiated, they often end prematurely (Ryan \& Thompson, 2013). While young people experiencing homelessness demonstrate remarkable resilience in harnessing individual and social coping strategies to survive (Thompson et al, 2016), personal histories of being let down or mistreated by formal support systems means many young people are coping on their own, civically disengaged, and without ample access to social capital (Bender et al, 2018).

Service systems should thus attempt new models for engaging young people experiencing homelessness to build stronger, more lasting supportive relationships. Mutual aid, or peer-to-peer support, may offer such engagement through shared lived experiences and an understanding of the multiple intersecting vulnerabilities often faced by youth who access services. This paper describes the rapport building, or engagement, process from the perspective of peer support specialists. Developed through a participatory research process, our findings aim to describe in detail how peers uniquely initiate contact and build connection with young people experiencing homelessness. Learnings from peer strategies may be useful to more conventional service providers seeking connective and long-lasting relationships with young people and may inform organizations considering mutual aid programming. 


\section{Literature Review}

Mutual aid has a long history within mental health movements, wherein peer-to-peer support for those with shared lived experiences has emerged as an alternative care practice amidst adverse experiences with traditional service providers (Mead \& MacNeil, 2006). Yet, peer support has received little empirical attention for its relevance for young people experiencing homelessness. In the past decade, the Substance Abuse and Mental Health Services Administration (SAMHSA) has invested funds in developing peer support programs for adults experiencing homelessness, citing this approach as fundamental to recovery (oibiSAMHSA Advisory, 2006); SAMHSA has begun to develop guidelines (Steacy, 2011) and standards to guide peer-to-peer work with adults (MacNeil \& Mead, 2003). This citizens-helping-citizens model has been associated with health outcomes, such as promoting hope for recovery, reducing stigma, increasing empowerment, self-esteem, self-confidence, and community integration for individuals who receive peer support (Repper \& Carter, 2011). Another recent review of adults and young adults experiencing homelessness receiving peer support (backed by professional training and supervision) reported improved quality of life, fostering social support, working towards reduction in drug and alcohol use, and promoting physical and mental health (Barker \& Maguire, 2017). Furthermore, adult peer workers benefit from serving in a supportive role, with increased confidence, self-esteem, and personal recovery (Bracke et al., 2004). Based on these findings, the mutual aid model may hold promise for young people experiencing homelessness while also providing a sense of meaning and civic engagement for those serving in the peer worker role.

Unfortunately, the knowledge base regarding mutual aid for young people is very limited (Ansell \& Insley, 2013). Only a handful of studies have investigated peer programming with 
youth populations, primarily in schools (e.g., mentoring younger students (Karcher, 2005), supporting peers with disabilities (Carter \& Kennedy, 2006) and in postsecondary education with students of color (Harper, 2006) and first generation students (Dennis, Phinney, \& Chuateco, 2005). Even fewer studies have examined peer support models with marginalized young people such as those involved in child welfare (Cherna, 2012) or those with mental health challenges (Butman, 2009).

Misconceptions of youth experiencing homelessness as unmotivated, unreliable, or incapable may have prevented mutual aid models from proliferating in youth homelessness services more broadly. While young people certainly face many risks while homeless, they also garner incredible strengths and resiliencies that would suit them well for engaging in mutual aid programming. Young people experiencing homelessness already form their own peer networks and support systems. They continually rely on one another for sharing of information and resources, developing informal networks that help them meet their basic needs (Bender et al., 2007). For example, young people often construct "street families" and "self-supportive" kinship networks in response to disconnection from families of origin (Smith, 2008). Furthermore, despite assumptions that youth are apathetic, our own research demonstrates these young people seek opportunities to contribute to their community in meaningful ways (Author Name Redacted., 2018). When prolonged, flexible, youth-centered relationships can be built, young people are motivated and persist toward reaching identified goals and contribute meaningfully (Bender et al., 2017). While youth experiencing homelessness face significant societal disaffiliation, they simultaneously demonstrate strengths and resiliencies well-suited to both provide and receive peer-to-peer support. 
Although few studies exist focused on understanding mutual aid programs among young people experiencing homelessness (Barker \& Maguire, 2017), the emerging research is promising. Kidd et al. (2019) studied the role of peers during a 6-month structured intervention in supporting youth exiting homelessness. Youth participants involved in this study reported that, unlike traditional service providers, peers were uniquely able to build community and be versatile in relationships with youth, often engaging with youth during social outings and handson projects. Study participants who had higher levels of engagement with peer workers had significantly more engagement with employment and education and/or volunteering at the end of the study period compared with the group which had no or low engagement with peers (Kidd et al., 2019).

The current study aims to build upon this emergent literature by using participatory research methods to understand how peers, in their roles as professionals with shared lived experiences, uniquely initiate contact, and build connection with, young people experiencing homelessness. Such investigation may inform service agencies considering development of mutual aid programs to build connections with youth and better support their needs. In addition, service agencies struggling to engage young people to partner in their growth and goal achievement may find relevance in peers' relationship building process in contrast to more conventional intake and assessment processes.

\section{Methods}

\section{1. University-Community Partnership}

This research was initiated by a community-based program, Recovery Support Services (RSS), which is embedded in a broader organization, the Colorado Coalition for the Homeless 
$(\mathrm{CCH})$. The community-based team sought partnership with academic researchers to study RSS's peer support program in order to deepen systematic descriptions of their program (roles, philosophies, challenges) and to inform the field and empirical literature about peer work with young people experiencing homelessness. To increase transferability, the organizational context in which this research took place, including its programming, history, philosophy, and structure, is important to describe.

CCH serves over 20,000 adults, families, and young people experiencing homelessness annually, through providing a combination of housing, integrated healthcare, and supportive services. Embedded in the Department of Outreach and Engagement, RSS serves youth experiencing homelessness who also experience challenges related to their mental health and/or substance use. It is both an outreach and intensive services program. RSS assists these young people in their recovery by providing wrap-around supportive services, including clinical case management, peer support and linkage to integrated healthcare. RSS outreaches approximately 125 individuals annually. RSS is centrally located in downtown Denver, although much of the peers' work took place in the community: public spaces, parks, youth shelter and drop-in centers, transitional housing, and other social service locations.

Peer support programming at $\mathrm{CCH}$ began 15 years ago (2005), wherein a small group of peer staff members supported adults who were participating in substance use treatment services throughout the larger organization. The RSS program at the center of this study was awarded a community mental health services block grant from SAMHSA, through the Office of Behavioral Health, to hire two peer support specialists to specifically support young people experiencing homelessness in 2016. This grant funds RSS peers to engage with youth through flexible service 
outputs focused on SAMHSA's principles of recovery (housing, healthcare, meaningful daily activity, and community connection).

The philosophy guiding the RSS peer program provides an overarching framework for the work. As described at RSS, peers' first priority is to build relationships with young people experiencing homelessness - to get to know them. It is certainly an objective/hope that peers will ultimately serve as catalysts for change for some young people — that they will walk beside young people and support them to engage with resources that align with the young people's change goals. However, whether the young people choose to pursue change and how they go about it is ultimately up to them. A peer support specialist role often includes assisting clients in accessing the resources and developing the personal skills they need related to housing, healthcare, activities in the community.

Peer roles are flexibly structured. Peers work between $20-40$ hours per week; their work is youth-centered, and regularly involves mentoring youth regarding goal setting, problem solving, skill-building, navigating healthcare and service systems, and building community connections. Peers also lead groups for youth, complete necessary paperwork, and engage in weekly team meetings and supervision. Peers took direction from the young people in terms of how often to meet. In some relationships, a peer and a young person would spend several hours a week together and in others they would see each other once a month; sometimes contact within a relationship would ebb and flow between intensive and intermittent work. Peers worked with some young people once or twice and with other young people for multiple years.

Peer input was incorporated across levels of the organization. During the development of RSS's peer program, RSS leadership and supervision staff continually invited communication from newly hired peer support specialists about their ideas and input about the program. RSS 
supervisory and leadership staff also offered ongoing opportunities for feedback from peers about program needs and suggested modifications based on their lived experiences and their roles. Because of the uniquely flexible grant funding, along with the value $\mathrm{CCH} / \mathrm{RSS}$ places on peer support as a pathway to recovery, RSS was able to allow for iterative program modifications, small caseloads, and long relationships with youth. RSS was required to report service outputs versus outcomes to their granting body, which allowed for flexibility from peers to do relational and youth-centered work.

\section{2. Sample}

The goal of this project was to use the inherent knowledge already present in the $\mathrm{CCH}$ team to generate and share knowledge based on their experiences; thus, the university researcher helped to facilitate a process in which the $\mathrm{CCH}$ team members served not only as co-researchers designing the study, but also using purposive sampling, as $\mathrm{CCH}$ team members served as participants in this study. Participants shared their knowledge and experience systematically through interviews and journaling. The sample included the RSS program manager who helped develop the adult peer program over an 11 year period then supported development of the youth program, the RSS peer supervisor and clinician who provided individual supervision and support to peers, and two peer support specialists who had been working for RSS for the past 1-2 years. In addition, a provider of adult peer services at $\mathrm{CCH}$, who provided group and individual supervision to the peer workers in this study, participated in interviews but was not involved on the participatory research team.

\subsection{Participatory Design}


This team used a qualitative participatory design, rooted in a participatory action research model (Lewin, 1946). In all phases of the research process, our team of academic and community-based researchers has embraced and prioritized participatory principles, including power-sharing, co-learning, and shared decision-making (Bergold \& Thomas, 2012). These principles refer to the values which guided the team's work towards equity in task delegation and decision-making rather than simply relying on positional power or traditional research hierarchy to guide team processes. Traditional qualitative methods were continually informed by, or adapted, to prioritize the aforementioned participatory principles.

Composed of a university-based researcher, two graduate students, a community-based program administrator, supervisor and two peer support specialists, our team valued the diversity in our experiences, perspectives, and knowledge. We particularly elevated the value of lived experience as a source of knowledge and evidence throughout our process. Co-learning occurred throughout our project: university researchers trained the community-based team members on data collection and analysis, and the community-based team informed researchers on the mutual aid program, best methods for understanding it, and how to interpret research findings. The team worked collaboratively over a three-year period from conceptualizing the research questions through disseminating our findings.

All team members contributed to the study design. This included developing research questions guiding the study as well as determining what methods might be used to collect data. The team decided to conduct semi-structured interviews and gather journal entries as means of data collection, and the team collectively contributed possible interview questions and journal prompts to be included. The academic researcher combined team members ideas and provided a collective draft of data collection materials for further feedback and revisions before data 
collection tools were used. All team members, both academic and community-based, took part in the human subjects (CITI) training and were added to university IRB. The community-based organization's own internal IRB reviewed ceded approval to the university IRB.

University-based researchers conducted semi-structured interviews with each of the community-based team members (the peer support specialists, the program administrator, and individual and group supervisor). The guiding interview questions for peer support specialists covered several topics: motivations for being a peer support specialist (e.g., Why did you want to work as a peer worker? Why do you continue?); purpose of the peer role (e.g., How would you describe your job and role? When are times that you think about working with a youth differently than how non-peer staff might approach a youth?), how peers establish trust and engage young people experiencing homelessness (e.g., How do you uniquely build trust and relationships with young people? How do you make decisions about when to share your own life experiences with youth?), areas for improvement in the peer model (e.g., What are the tensions and benefits of having experienced homelessness when working with young people who are currently homeless?; If the peer program landed a huge grant and asked you how to spend the money, what would you suggest?); support needed for peer support specialists (e.g., How are you currently being supported at work? What do you need that you don't have that would help you do your job better?), and perceived needs and successes of youth working with peers (e.g., How do you identify when you have progress with youth? When do you feel like you are doing your job well? What was a recent breakthrough moment you had with a youth?).

Interview questions for supervisors and the administrator varied slightly from peer interviews, although they covered many of the same topics. In addition to eliciting the vantage point of the supervisor/administrator on these topics, interviews also included greater history 
about the program, its development, philosophy, and changes over time. Each interview lasted 1.5 hours, were audio recorded, and transcribed verbatim. The administrator and group supervisor each participated in one interview, while the two peer support specialists and the peer supervisor participated in two interviews each to allow enough time to explore all questions.

Journaling has been identified as an advantageous method for eliciting deep insights as they occur in the field (Hayman, Wilkes, \& Jackson, 2012). Our team developed a semistructured journal guide; each peer conducted six weeks of journal entries (two to three times per week) which were analyzed collectively by the team. Journal prompts asked peer workers to, at the end of a workday, report: (1) one positive feeling they had in their work (e.g., excited, happy, motivated, helpful, optimistic) and (2) one challenging feeling they had in their work (e.g., frustrated, anxious, uncomfortable, stuck, disconnected) and to then describe in detail what happened that lead to those two feelings. They then (3) chose one reflection question from a list to answer (e.g., how did you attempt to build trust? How did you navigate power dynamics today, when and how did you decide to share about your own experiences today?).

\subsection{Participatory Data Analysis}

To begin the participatory data analysis process, the team divided up the journals and transcripts. Two coders (at least one being a peer support specialist) coded each document. The team coded using a template analysis based on the guiding research question (philosophy/roles; actions/behaviors; challenges; successes; supports needed). The team applied a color code for each category in the template, then, inductively began to identify codes by colored sticky notes.

Through a series of analysis retreats, the team followed several steps to analyze the coded documents: (1) shared all the codes of a specific color using sticky notes on a wall; (2) clustered 
codes that grouped together on similar "clusters" as a team onto large sheets of paper; (3) labeled "clusters" of codes (emerging themes) with a name that characterized the codes within the clusters; (4) conducted collective memoing as the team discussed themes aloud - this added details about how the theme was experienced in practice; (5) collective memos were written in notes alongside the sub-coded sticky notes and audio-recorded for further reference; (6) organized the themes in relationship to one another into an overarching framework.

Throughout the participatory analysis process, the team emphasized the value of multiple perspectives by assuring that every document had the perspective of both a university-based and community-based researcher. Throughout analysis, the goal became less to replicate one another's codes (i.e., inter-rater reliability), but rather to prioritize the elicitation of $d u a l$ perspectives. These dual perspectives informed the development of rich, nuanced themes that center the lived experiences of the community-based researchers while utilizing rigorous research methods.

The team then wrote up the themes with an effort toward capturing these dual perspectives. First, team members formulated written descriptions of each theme based on subcodes from sticky notes and collective memos. For each theme written by a university-based researcher, a community-based researcher provided a more nuanced description, incorporating their lens and voice. Similarly, for each theme written by a community-based researcher, a university-based researcher provided the first round of revisions, often adding organization and structure to the summaries.

This dual perspective approach is evident in the narrative form our results have taken in this article. As a final step, all final themes were translated into a first-person narrative so that 
findings are read as if from the direct perspective of a peer support provider, to align with the team's value of lived experience guiding knowledge generation and dissemination.

\subsection{Positionality Statement}

This research team of seven individuals has sought to take a reflexive stance throughout this research process. In doing so, the team honors multiple ways of knowing: lived experience, educational experience, prior research, and direct practice. Discussions of the variety of experiences and identities that exist on this team have been central to our shared dedication to the success of a PAR model. The team hosts a variety of experiences with regard to homelessness, including having experienced housing insecurity (three people), having experienced street-based homelessness (two people), having direct service experience with young people experiencing homelessness (six people), and all seven members having conducted research with young people experiencing homelessness (ranging from several years to this being their first research experience). Regarding formal education, our team has one member who is working toward a BA degree, one who holds a BA, and all other members hold a masters or PhD. The gender composition of this team comprised of 4 cis-female identifying adults, 1 cis-male identifying adult, 1 adult who brings trans identity to this work (gender identity for one member was not available at this time). All members of this team identify as white. Our approach to the limitations of our project caused by our whiteness and privilege is highlighted by one of our white, cis-male team members. He states, "I am privileged in almost any way you can imagine. With that privilege comes responsibility (obligation may be a better word) to deconstruct the social system that grants me privilege and critically examine-- and actively counter-- my participation in that system- conscious and unconscious, active and passive." We have been 
intentional about leaning into our strengths and unique vantage points, whether these

perspectives emerged through traditional or non-traditional forms of training and experiences.

\section{Findings}

Relationships are central to peer work. Through their journals and interviews, the peer workers articulated central processes that underly the initiation of relationships between peer workers and youth. See Table 1 for descriptions of the themes and subthemes emerging from our analysis. The results are written in the first-person perspective from peer workers, to center their expertise and experience. An ode to complexity: it would be unrealistic to expect that all peer/youth relationships follow the same routes, or that these relationships start with the same set of conditions. Every peer/youth relationship-assembly is unique. Recognizing this constellation of this uniqueness, we present a framework for how things tend to go.

[Insert Table 1 here]

\subsection{Initiating Peer-Youth Relationships}

4.1.1. Becoming a Familiar Face. When I'm in the very beginning stages of building a peer relationship with a young person, I will often just hang around in spaces where young people spend their time -- like the drop-in center or the shelter -- or other public spaces. By doing this, I'm hoping to show youth that I'm available to talk if they want... but that they don't have to. As I hang around, I've learned to do kind of a dance - figuring out when to enter, or when to stay out of a conversation. I've become very aware of nonverbal cues. I've also had to get comfortable with silence or the pull to "do something helpful." Sometimes I really am just standing there. In those moments, I remind myself that becoming a familiar face and having 
informal conversations is a critical part of the relationship-building process in showing youth I'm safe, that I'm cool to talk to. That I'm available and trustworthy, and also professional.

It's important that I go to a lot of different spaces, because that's how youth start to recognize me. They might be hanging out at the drop-in center and recognize me from earlier at the shelter, or the park, or a transitional housing program. I find that it's reassuring for youth to see me just showing up in these spaces, being comfortable. But it isn't always easy to be comfortable. When you've been in similar institutional environments, it is easy to feel like the "new kid" in the halfway house or the new kid in the shelter, because you were that. But your personal history can also be helpful -- you have an idea of what the participants in the current environment are going through. When I am first getting to know a young person, I do often share my lived experience to establish that we have common ground. So, it can be uncomfortable and useful - it makes you think, "how can I make the space more welcoming, or comfortable, or safe?"

4.1.2. Identifying as a Peer. People don't just immediately know I'm a peer. I often get the question, "are you staff?" Or, sometimes I get misidentified as a young person seeking services. Often I get treated in a dismissive way by other service providers. In these moments, I have to remind myself, "I'm a Peer Support Specialist." That it's my job to be there, and also that I have shared experience, which positions me to connect with young people in ways that aren't accessible to traditional service providers.

Still, identifying as a peer has risks. I am often hesitant to bring up the name of the agency I work for, because it's a reminder of youths' homelessness. It may lead someone to retreat, especially if they think that my priorities as a peer are purely motivated with my work role, or 
with more formal services - or if they think I'm a traditional service provider. I want to be transparent about my role, but I also don't want to put the youth in the role of a formal "client."

This requires skill. I own the reality of my position: I $d o$ have shared experience. I $d o$ have financial gain in my role, and I am also genuinely interested in knowing youth. I don't have a formal agenda, but there are privileges and power that I bring to the relationship. The boundaries are subtle -- almost a plausible deniability, or suspension of disbelief. I have to be clear that I am at work, as a peer, and I'm not just hanging out as friends. But then both me and the youth kind of have to forget that. There are moments that are hard to forget that - like if I meet a youth for coffee, I have to do the mental gymnastics of deciding how money gets spent. Is my program going to pay for black coffee or a mocha (a \$2 coffee or a \$5 coffee)? Are we getting just coffee, or food too? How do I feel about being the person with the financial power?

Embodying my role requires me to be in tune with who I am as a peer, but also with who I am as a human being in the relationship.

4.1.3. Formalizing the Relationship. Before a youth is enrolled in the program, I might subtly invite connection -- a "soft invitation" - coffee, something like that. After youth become more familiar with me, I may give a "hard invitation" to explicitly engage in peer services, at which point they become enrolled in the program.

Many relationships with youth exist exclusively within the container of youth spaces - often, formal or scheduled meetings never happen. Even then, I can be very supportive of youth -through conversation, through modeling recovery, through hope. Conversations may feel very casual, but often youth are bringing up vulnerable and heavy topics. Many of them are starved for connection. Once I'm a familiar face, they may come to me to process things, even if we 
don't have a formal relationship. Sometimes a young person perceives my peer role as getting paid to hang out. Ultimately, I would rather they feel like we're "just hanging out" than it feel clinical and formal, or like they are interacting with "staff."

This can make some things awkward - for example, broaching the subject of completing paperwork often feels awkward -- a formality that I would rather not bring into my relationship with the young person. The process of filling out paperwork often feels like it doesn't align with the otherwise organic ways we relate to one another. I have to be transparent about what I am doing and why, and let them know they can choose not to answer anything they don't feel comfortable with. It's not that they're sick and I'm well, but rather that we're both growing along parallel lines -I'm just further on the path.

\subsection{Building Connection}

4.2.1 Same Side of the Glass. Most people accessing mental health services have had some experience with feeling like service providers were "on the other side of the glass:" enforcing a pathologized $u s$-and-them dynamic between staff and clients. I want to make it clear to my clients that I feel a sense of solidarity with them -- that I am "on their side of the glass." I express this in an immediate willingness to admit the glaring flaws of mental health services and service providers.... in an experience-focused lens, rather than using the dominant lens and language of the APA, DSM, and other models of pathologizing. For example, I use the term "people who experience psychosis," or even "people who experience breaks with consensus reality," rather than mentioning and therefore reifying the diagnosis of "schizophrenia." This normalizes psychological diversity and gives me more avenues to skillfully bring up my own lived experience. 
4.2.2. Autonomy and Availability over Agenda. Showing up and being present are the most important parts of being a peer. I try to drop any checklist, treatment plan, and expectations with youth. The questions I ask aren't programmatic, and the activities I invite youth aren't explicitly "therapeutic" - they're more about exploring their identity, or having new experiences - like going shopping for clothes, or going to a coffee shop. Trying to think of things to do together rather than thinking of how to "help" or "fix" youth is so critical, especially at the beginning stages of building a relationship. Attempting to "build trust" can come off as inauthentic - so I try and connect in the way I would with a new acquaintance.

Youth are often overwhelmed by service providers offering resources, so many of which are high barrier or behind frustrating bureaucratic walls. So, it's important that I offer value by simply showing up as authentic. This is the best way to build connection. I show up, share space, and find joy with youth. I ride the ups and downs with them, while holding hope for them and having belief in them.

4.2.3. Creating a Container for Acceptable Failure. Youth may make choices that wouldn't be supported in formal services. I've been there. They might not show up for groups or appointments, they might put themselves in what could be seen as dangerous or unhealthy situations. Or, say you set up a first formal meeting and they miss it. Or, you're working with someone who relapses after 9 days sober - as a peer, and perhaps an alcoholic yourself, you may be frustrated they miss the meeting, but you also may experience their relapse quite viscerally.

Maintaining a non-judgmental attitude is the most critical skill I can offer as a peer working with young people experiencing homelessness. There's no "three-strike rule" if someone misses an appointment or doesn't meet "treatment goals." I try to understand and meet youth where they're 
at -- emotionally, cognitively, behaviorally -- and to offer acceptance even during times when their decisions are difficult for me to make sense of. This can be hard - as humans, we all have judgments. And frustrations. And disappointments. Sometimes people will share a lot, even during first interactions and you really start to care a lot about them. Youth are so used to having authority figures be disappointed in them - so I have to create a safe container of non-judgement- including not judging what others might think of as "failure." I've "failed" too, maybe even in similar ways. I try to normalize their experiences - sometimes by sharing my own.

\section{Discussion}

This study describes the ways peers (employed support providers with lived experience of homelessness) uniquely build relationships with young people experiencing homelessness or housing instability. Peer work elevates the centrality of authentic connection with young people, while employing a noticeably informal, casual, and flexible approach compared to traditional entry into youth-serving organizations. Traditional service models have been shown to estrange young people (Altena et al., 2017). In contrast, getting to know young people -- and providing the space for young people to get to know peers -- means allowing time for genuine co-creation of relationships in a non-directive and casual manner. Such relationships honor and respect the young people as humans rather than as clients to be "changed" or "fixed."

Peers' nonjudgmental approach may allow for more authentic relationship building, as well as greater understanding of young peoples' voices and perspectives. Shared lived experience may allow for more easily embracing such nonjudgement. When building relationships with peers, there is space for youth to fail, grow, and feel supported as they are. Young people are often able to relax and feel familiarity around peers; such familiarity creates a sense of community and relationship distinct from the programs offered by more traditional 
providers. It is likely that such community and sense of connection may result in other positive benefits; previous research by Kidd et al. (2019) has found that such engagement with peers enables community building, fostering significantly more youth engagement with employment and education than youth who did not work with peers.

Peers also may bring with them experiences of marginalization based on other oppressed identities they hold (e.g., gender identity, race, sexual orientation, trauma) as well as stigma or objectification (sometimes perpetuated unwittingly by service providers). Recognizing and sharing these experiences allows peers to join with young people in face of the experiences of stigmatization, homophobia, racial prejudice, transphobia, and other axes of oppression which often intersect with homelessness. Such shared experiences are critical not only in building connection and safety, but also in supporting young people's identity development and resilience (Paceley, 2016). Yet, even when experiences of homelessness are shared, barriers to connection still exist. Both peers in our study were White, which undoubtedly impacted how they engaged with young people. Accounting for both shared and divergent identities is critical in understanding how peers build relationships.

Peer support has a long history within the mutual aid movement and has been particularly politicized when applied to health and mental health practices. Peer support for mental health grew out of a shared response to negative experiences with mental health providers and systems, such as over-medication and rights violations of 'patients' (Mead \& MacNeil, 2006). By way of example, the Independent Living movement was developed by and for people with disabilities to create care services and advocacy, and the Hearing Voices Network was created for mutual support between people who hear voices or other similar sensations. Borne from dissatisfaction with traditional service systems, peer support is built upon an ethos of "mutuality" and "mutual 
responsibility" (Mead \& MacNeil, 2006) versus a hierarchical helping relationship. Furthermore, peer work embraces the assumption that "growth happens in a context and that in order for growing things to emerge, environments must change to accommodate that growth" (Deegan, 1996). The peer support specialists in our study are employed by a traditional service system, yet work towards mitigating hierarchical structures by providing flexible and authentic support through individual relationships and supportive contexts. The peer model embraces the assumption that if change will occur, it will happen on the young person's terms.

While many youth-serving organizations aspire to provide services through youthcentered and strength-based models, peers are in position to actualize such approaches. Peer work, as described in this study, stands in contrast to many conventional service structures, which often include formal standardized assessments upon entry. Although rapport building is often emphasized in staff training, it may be viewed as an item to "check off" in order to prioritize service plans and meet expected agency outcomes. Conventional models may compromise opportunities for authentic relationship building; service providers may lead a change effort rather than a young person, and/or jump towards assessment and change before building connection. Such models may lead young people to experience discrimination and stigma (Hudson et al., 2010), to be apprehensive to engage in formal services (Naert et al., 2019), and to ultimately disaffiliate from, and cope without, services (Bender et al., 2018).

Many traditionally trained clinicians are familiar with the work of humanistic and relational clinical theorists Carl Rogers and Irvin Yalom. Rogers' (1959) client-centered approach emphasizes unconditional positive regard and empathic understanding. Yalom (2002) affirms the view of the patient-client relationship as one of fellow travelers and advocates for instilling hope and being transparent to foster engagement and connection. However, many 
clinicians may be unfamiliar with the history of mutual aid approaches to mental health, even though their respective philosophies run parallel to one another. While clinicians may have to learn person-centered approaches, peers embody these values. Peers are uniquely positioned to offer attuned empathy and unconditional positive regard as they walk alongside young people while carrying an intimate understanding of youth homelessness. Peers model successes in navigating their own recovery, ultimately instilling hope. Peers also provide corrective emotional experiences (Yalom, 1985) by authentically interacting with young people in ways that few (or no) service providers have before.

Mutual aid has much to offer in terms of informing clinical approaches that engage young people experiencing homelessness to experience greater self-determination and selfactualization. The peer support model in this study centers relationships, not change. Having peers on teams may also hold accountable the systems who aim to provide relationship-based and person-centered support. Were the field to offer more mutual aid programming, young people may be better engaged and supported in their healing and recovery.

\subsection{Limitations}

There are inherent limitations in using the PAR approach to inquiry. This approach could invite critiques, especially regarding objectivity and group think. However, this sort of approach in fact accounts for biases early, and at every stage in the process (Cammarota \& Fine, 2008). Objectivity is not the goal; an iterative reflective process with the group allows for depth often unattainable in other research methods, especially through centering lived experience and valuing multiple ways of knowing.

Given the emergent nature of peer work with young people experiencing homelessness, there are limitations in presenting a singular portrait of peer support as we have done here. There 
are also limitations of concisely describing complex relationships; these relationships happen in real time, real space, and real human dynamics. We chose to present the findings through the peer perspective to provide a window into the relationship development stage between peers and young people experiencing homelessness. Yet each relationship is unique and contextually bound. Each peer is different, and all face unique complexities in navigating their work. While we presented one universal image, we also sought to present "the dance" that peers navigate in the relationship-initiating and relationship-building stages of their work. By choosing to present our findings through peer voices, we hope to normalize the complexities and nuances inherent in peer work, while also providing a set of themes from which peers and peer programs may conceptualize the relationship-building stage in their own work.

Our findings reflect a peer program embedded in an organization contextually bound by specific structures and values. We've done our best to provide context to our findings to aid transferability; it is likely that peer programming operating in organizations with different philosophies (e.g., where peers have less autonomy and power) would look quite different, and as a consequence, may not allow for the work described here. Lastly, relationships do not always happen in the distinct stages we have presented here - the course of each relationship is different. However, focusing on the first stages of initiating and building relationships allows us to "zoom in" on the rapport-building phase often glossed-over in the literature; this may be particularly important given the unique positionality of peers as they navigate this stage of their work.

\subsection{Implications \& Conclusions}

Our study provides an illustration of how peers build relationships with young people experiencing homelessness, a stage of engagement which proves challenging for many service providers given the disaffiliation young people experiencing homelessness often face. These 
findings have implications for organizations aiming to engage young people experiencing homelessness, especially those which are considering implementing peer programming.

The flexible peer work described here creates inherent tensions for peers to navigate. Peers often must confront their positioning within the service relationship and with colleagues, whether deciding how to spend money when going out for coffee with youth or educating a colleague about their role. Being perceived as a youth by young people and providers requires careful disclosure of their role and lived experience. Desires from young people for friendship or deeper relationships requires clarifying the peer role without shaming or rejecting young people. Navigating personal history, as it comes up in the work, becomes incredibly important, especially when reminders emerge from being in similar spaces at earlier times in their lives.

Supervision can offer support to makes sense of the inherent complexities and tensions in peer work. On our team, these conversations were not directive, nor do they always result in one clear answer (much like peer work). Rather, supervision was a space for peers to sift through the tensions. The supervisor on our team approached supervision with genuine curiosity about peers' ideas, and invited peers to share their proposed courses of action. Peers harness their lived experience to build relationships with young people. Accordingly, supervisors should invite peers to share how their work is impacting them, including how sharing their own experiences has felt for them, what stories they have heard from youth that mirror their own experiences, and how such similarities affect them. Peers on our team described being able to respond to young people in an authentic and nuanced way because they could process their complex feelings about situations and relationships with youth in supervision.

In short, the supervision model must engage peers in a parallel approach to the peer model of engaging young people. It could be easy for supervisors to default to a more 
conventional directive supervisory style; particularly in peer work, it is important that peers are centered and given power to make decisions in their work. There has been recent advocacy in the field for peers to be supervised by other peers with lived experience, such a model may allow for the support, flexibility, and authenticity needed in peer supervision.

To successfully support the peer work described here, peers and this relationship-centered approach must be valued at every level of an organization. The work described in this study involves more a more flexible, and often slower, approach compared to the brief services offered in most service settings. Organizations (and administrators) need to embrace patience and flexibility; develop programs and policies that allow for peer autonomy; and center knowledge from peers, rather than merely creating 'peer friendly' environments. To do so, funders and organizational leaders must shift from prioritizing more traditional outcomes (e.g., number of youth served, percentage housed) to valuing outputs, including actions taken by peers, peers' ability to bridge young people to other supports, and length of youths' engagement in peer services.

For providers without lived experience, findings provide a point of reflection about the ways to meaningfully initiate relationships by taking time to authentically get to know young people. Providers without lived experience may learn from peers' processes and may benefit from assessing the ways they may integrate such philosophies and strategies into their work with young people. They should also consider the limitations in implementing such work without lived experience. Finally, providers with and without lived experience can advocate for peers by uplifting peer work as a valuable approach to working with young people experiencing homelessness. 
In conclusion, developing support for peer programming introduces a way of engaging relationships with young people which centers their agency. Establishing conditions for greater affiliation requires authentic relationship development and work towards healing long histories of trauma and rejection that young people have experienced -- even from service providers. We suggest that providers and organizations shift responsibility for engagement away from solely being placed on young people, and towards shared responsibility for meaningful relationships and authentic partnership with young people. Providers must take responsibility for understanding young people and carefully considering their histories and the contexts of their lives as they respond to them. Peers are uniquely positioned to do and, in so doing, may build deeper and more organic relationships with youth. If service systems embrace these principles and practices, we may see a shift towards meaningful engagement, and success towards outcomes valued by young people and social service systems alike. 


\section{Funding}

This material is based upon work funded by the Office of Research and Evaluation at the Corporation for National and Community Service (CNCS) under Grant No. 18REHCO001 through the Community Conversations research grant competition. Opinions or points of view expressed in this document are those of the authors and do not necessarily reflect the official position of, or a position that is endorsed by, CNCS.

\section{Acknowledgement}

Our team would like to thank the young people who, in relationship with our team members, have informed the ideas and concepts that have evolved in our work. Our team would also like to acknowledge Dana Feeny for her contributions in interviewing, coding and conceptualizing the ideas presented here. 


\section{References}

42 U.S.C. $§ 11434 \mathrm{a}[2][\mathrm{B}]$.Title 42 - The public health and welfare chapter 72 - Juvenile justice and delinquency prevention subchapter III - Runaway and homeless youth Part F - General Provisions Sec. 5732 - Evaluation and information

Aceves, L., Griffin, A. M., Sulkowski, M. L., Martinez, G., Knapp, K. S., Bámaca-Colbert, M. Y., \& Cleveland, H. H. (2020). The affective lives of doubled-up Latinx youth: Influences of school experiences, familism, and ethnic identity exploration. Psychology in the Schools. https://doi.org/10.1002/pits.22391

Altena, A., Krabbenborg, M., Boersma, S., Beijersbergen, M., Van Den Berg, Y., Vollebergh, W., \& Wolf, J. (2017). The working alliance between homeless young adults and workers: A dyadic approach. Children and Youth Services Review, 73, 368-374. https://doi.org/10.1016/j.childyouth.2017.01.015

Ansell, D. \& Insley, S. (2013). Youth peer-to-peer support: A review of the literature [PDF]. Youth Move National. Retrieved from https://gucchdtacenter.georgetown.edu/resources/Webinar $\% 20$ and $\% 20$ Audio $\% 20$ Files/Yout h\%20Peer\%20to\%20Peer pubs $\% 20$-\%20Literature\%20Review\%20FINAL.pdf

Auerswald, C. L., \& Eyre, S. L. (2002). Youth homelessness in San Francisco: A life cycle approach. Social Science \& Medicine, 54(10), 1497-1512. https://doi.org/10.1016/S0277$\underline{9536(01) 00128-9}$

Barker, S. L., \& Maguire, N. (2017). Experts by experience: Peer support and its use with the homeless. Community Mental Health Journal, 53(5), 598-612. https://doi.org/10.1007/s10597-017-0102-2 
Barrett, J. (2019). Youth who are homeless: A closer look. Presented at Seton Hall Petersheim Academic Exposition, South Orange, New Jersey. Retrieved from https://scholarship.shu.edu/cgi/viewcontent.cgi?article=1080\&context=petersheim$\underline{\text { exposition }}$

Bender, K., Barman-Adhikari, A., DeChants, J., Haffejee, B., Anyon, Y., Begun, S., Portillo, A., \& Dunn, K. (2017). Asking for change: Feasibility, acceptability, and preliminary outcomes of a manualized Photovoice intervention with youth experiencing homelessness. Children and Youth Services Review, 81, 379-389. https://doi.org/10.1016/j.childyouth.2017.08.028

Bender, K., Begun, S., Dunn, K., MacKay, E., \& DeChants, J. (2018). Homeless youths’ interests in social action via Photovoice. Journal of Community Practice, 26, 107-120. https://doi.org/10.1080/10705422.2017.1413027

Bender, K., Begun, S., Durbahn, R., Ferguson, K., \& Schau, N. (2018). My own best friend: Homeless emerging adults' hesitance to seek help and strategies for coping independently after distressing and traumatic experiences. Social Work in Public Health, 33, 149-162. https://doi-org.du.idm.oclc.org/10.1080/19371918.2018.1424062

Bender, K., Thompson, S. J., McManus, H., Lantry, J., \& Flynn, P. M. (2007). Capacity for survival: Exploring strengths of homeless street youth. Child and Youth Care Forum, 36, 25-42. https://doi.org/10.1007/s10566-006-9029-4

Bergold, J. \& Thomas, S. (2012). Participatory research methods: A methodological approach in motion. Forum: Qualitative Social Research, 13 (1). Art. 30, http://dx.doi.org/10.17169/fqs$\underline{13.1 .1801}$ 
Bracke, P., Christiaens, W., \& Verhaeghe, M. (2008). Self-esteem, self-efficacy, and the balance of peer support among persons with chronic mental health problems. Journal of Applied Social Psychology, 38(2), 436-459. https://doi.org/10.1111/j.1559-1816.2008.00312.x

Britton, L. \& Pilnik, L. (2018). Preventing homelessness for system-involved youth. Juvenile and Family Court Journal, 69(1), 19-33. https://doi.org/10.1111/jfcj.12107

Butman, M. (2009). Peer mentoring: Real recovery for young adults. Focal Point, 23(2), 28-31.

Cammarota, J., \& Fine, M. (Eds.). (2008). Revolutionizing education: Youth participatory action research in motion. Routledge.

Carter, E,. \& Kennedy, C. (2006). Promoting access to the general curriculum using peer support strategies. Research \& Practice for Persons with Severe Disabilities, 31(4), 284-292. https://doi.org/10.1177/154079690603100402

Cherna, M. (2012). Youth support partners: Building trust and improving service delivery for youth. Policy and Practice, 70(6), 28-29.

Combs, K. M., Barman-Adhikari, A., Begun, S., \& Rice, E. (2020). Relationships Between Parenting and Dangerous Substance Use Behaviors Among Youth Experiencing Homelessness. Journal of the Society for Social Work and Research, 11(1), 1-20. https://doi.org/10.1086/707341

Deegan, P. (1996, September 16). Recovery and the Conspiracy of Hope. Speech presented at There's a Person in Here": The Sixth Annual Mental Health Services Conference of Australia and New Zealand in Australia, Brisbane. 
Dennis, J., Phinney, J., \& Chuateco, L. (2005). The role of motivation, parental support, and peer support in academic success of ethnic minority first-generation college students. Journal of College Student Development, 46(3), 223-236. https://doi.org/10.1353/csd.2005.0023

Dworsky, A., Gitlow, E., Horwitz, B., \& Samuels, G.M. (2019). Missed opportunities: Pathways from foster care to youth homelessness in America. Chapin Hall at the University of Chicago [PDF]. Retrieved from https://www.chapinhall.org/wp-content/uploads/ChapinHall VoYC Child-Welfare-Brief 2019-FINAL.pdf

Harper, S. (2006). Peer support for African American male college achievement: Beyond internalized racism and the burden of "acting White." The Journal of Men's Studies, 14(3), 337-358. https://doi.org/10.3149/jms.1403.337

Hayman B, Wilkes L, Jackson D (2012) Journaling: identification of challenges and reflection on strategies. Nurse Researcher, 19(3), 27-31. https://doi.org/10.7748/nr2012.04.19.3.27.c9056

Hudson, A. L., Nyamathi, A., Greengold, B., Slagle, A., Koniak-Griffin, D., Khalilifard, F., \& Getzoff, D. (2010). Health-seeking challenges among homeless youth. Nursing Research, 59(3), 212-218. https://doi.org/10.1097/NNR.0b013e3181d1a8a9

Karcher, M. J. (2005). The effects of developmental mentoring and high school mentors' Attendance on their younger mentees' self-esteem, social skills, and connectedness. Psychology in the Schools, 42(1), 65-77. https://doi.org/10.1002/pits.20025

Kidd, S. A. (2007). Youth homelessness and social stigma. Journal of youth and adolescence, 36(3), 291-299. https://doi.org/10.1007/s10964-006-9100-3 
Kidd, S. A., Vitopoulos, N., Frederick, T., Daley, M., Peters, K., Clarc, K., Cohen, S., Gutierrez, R., Leon, S., McKenzie, K. (2019). Peer support in the homeless youth context:

Requirements, design, and outcomes. Child and Adolescent Social Work Journal, 36(6), 641-654. https://doi.org/10.1007/s10560-019-00610-1

Keeshin, B. R., \& Campbell, K. (2011). Screening homeless youth for histories of abuse: Prevalence, enduring effects, and interest in treatment. Child Abuse and Neglect, 35(6), 401-407. https://doi.org/10.1016/j.chiabu.2011.01.015

Kurtz, P. D., Lindsey, E. W., Jarvis, S., \& Nackerud, L. (2000). How runaway and homeless youth navigate troubled waters: The role of formal and informal helpers. Child and Adolescent Social Work Journal, 17(5), 381-402. https://doi.org/10.1023/A:1007507131236

Lewin, K. (1946). Action research and minority problems. Journal of Social Issues, 2(4), 34-46.

MacNeil, C., \& Mead, S. (2003). Discovering the fidelity standards of peer support in an ethnographic evaluation. [PDF] Retrieved from www.mentalhealthpeers.com

Mead, S., \& MacNeil, C. (2006). Peer support: What makes it unique. International Journal of Psychosocial Rehabilitation, 10(2), 29-37. Retrieved from $\underline{\text { http://citeseerx.ist.psu.edu/viewdoc/download?doi=10.1.1.584.6618\&rep=rep1\&type=pdf }}$

Morton, M.H., Chávez, R., \& Moore, K. (2019) Prevalence and correlates of homelessness among American Indian and Alaska Native youth. Journal of Primary Prevention, 40, 643660. https://doi.org/10.1007/s10935-019-00571-2 
Morton, M. H., Dworsky, A., Matjasko, J. L., Curry, S. R., Schlueter, D., Chávez, R., \& Farrell, A. F. (2018). Prevalence and correlates of youth homelessness in the United States. Journal of Adolescent Health, 62(1), 14-21. https://doi.org/10.1016/j.jadohealth.2017.10.006

Morton, M.H., Dworsky, A., \& Samuels, G.M. (2017). Missed opportunities: Youth homelessness in America. National estimates. Chapin Hall at the University of Chicago. [PDF]. Retrieved from https://voicesofyouthcount.org/wp-content/uploads/2017/11/VoYCNational-Estimates-Brief-Chapin-Hall-2017.pdf

Morton, M. H., Samuels, G. M., Dworsky, A., \& Patel, S. (2018). Missed opportunities: LGBTQ youth homelessness in America. Chapin Hall at the University of Chicago. [PDF]. Retrieved from https://www.chapinhall.org/wp-content/uploads/VoYC-LGBTQ-Brief-FINAL.pdf

Naert, J., Roets, G., Roose, R., \& Vanderplasschen, W. (2019). Fight, freeze or flee: Exploring youngsters' strategies in dealing with youth care interventions. Qualitative Social Work. https://doi.org/10.1177/1473325019882078

National Center for Homeless Education. (2012). Increasing access to higher education for unaccompanied homeless youth: Information for colleges and universities. Best Practices in Homeless Education Brief Series. Retrieved from http://dev.nche.seiservices.com/wp- content/uploads/2018/11/nche research pub.pdf

Paceley, M. (2016). Gender and sexual minority youth in nonmetropolitan communities: Individual- and community level needs for support. Families in Society: The Journal of Contemporary Social Services, 97(2), 77-85. https://doi.org/10.1606\%2F1044$\underline{3894.2016 .97 .11}$ 
Rahman, M., Turner, F., \& Elbedour, S. (2015). The U.S. homeless student population:

Homeless youth education, review of research classifications and typologies, and the U.S. federal legislative response. Child \& Youth Care Forum., 44(5), 687-709.

\section{https://doi.org/10.1007/s10566-014-9298-2}

Repper, J., \& Carter, T. (2011). A review of the literature on peer support in mental health services. Journal of Mental Health, 20(4), 392-411.

https://doi.org/10.3109/09638237.2011.583947

Rogers, C. (1959). A theory of therapy, personality and interpersonal relationships as developed in the client-centered framework. In (ed.) S. Koch, Psychology: A study of a science. Vol. 3: Formulations of the person and the social context. McGraw Hill.

Ryan, T. N., \& Thompson, S. J. (2013). Perspectives on housing among homeless emerging adults. Evaluation and Program Planning, 36(1), 107-114. https://doi.org/10.1016/j.evalprogplan.2012.09.001

Substance Abuse and Mental Health Services Administration Advisory (2006). SAMHSA issues consensus statement on mental health recovery. Washington, DC. U. S. Department of Health and Human Services. Retrieved from https://www.samhsa.gov

Smith, H. (2008). Searching for kinship: The creation of street families among homeless youth. American Behavioral Scientist, 51(6), 756-771. https://doi.org/10.1177/0002764207311986

Solomon, P. (2004). Peer support/peer provided services underlying processes, benefits and critical ingredients. Psychiatric Rehabilitation Journal, 27(4), 392-401. https://psycnet.apa.org/doi/10.2975/27.2004.392.401 
Steacy, A. (2011). Tips for peer support programs. Rockeville, MD: Substance Abuse and Mental Health Services Administration. Retrieved from http://homeless.samphsa.gov/resource/tipcs-for-peer-support-specialist-programs50689.aspx

Thompson, S., Ferguson, K., Bender, K., Begun, S., \& Kim, Y. (2016). Homeless emerging adults: A developmental perspective. In J. J. Arnett (Ed.), Oxford library of psychology. The Oxford handbook of emerging adulthood (p. 578-600). Oxford University Press.

Yalom, I. D. (2002). The gift of therapy: An open letter to a new generation of therapists and their patients. Harper Collins

Yalom, I. D. (1985). The Theory and Practice of Group Psychotherapy. 3rd Edn. Basic Books. 